\section{Appeal from Moscow}

SIR-I am appealing to you for help. For about seven years, I have been trying to leave the Soviet Union for Israel. All my aduit life (more than 20 years) I have worked in the field of experimental oncology and I have never had anything to do with any state or military secrets. Nevertheless, for the past seven years, I have been refused permission to leave the country and have been prevented from working in my field.

I am appealing to all my friends, to all my colleagues, to "the world of oncology" for help and sympathy. I am convinced an appeal from you to the General Secretary M.S. Gorbachev to permit me to leave the country will be considered with due attention and I will be permitted to realize my legitimate will.

Following the Geneva talks, relations are being restored between East and West and joint Soviet-American research projects are being set up in oncology; I therefore believe that such a request would be looked upon with understanding. A request from my US colleagues would be of particular value.

My own state of health and that of my mother make me anxious about any delay and I ask all of you "not to put off to do the good". You are my last hope. I believe in your solidarity and humanism.

IOSEF S. IRLIN

Moscow, USSR

\section{Helping Sakharov}

SIR-The letter by Erast B. Gliner', "Another reason for saving Sakharov", does more harm than good. By emphasizing the value of Sakharov's scientific contributions, Gliner reinforces the tendency of some scientists to protest against violations of human (and scholarly ${ }^{2}$ ) rights in proportion to perceived eminence of the individual.

The history of science shows that eminence is often accorded only posthumously. Thus, such a criterion for intervention is likely to be too late, especially where intellectual suppression has prevented younger scientists from realizing anything approximating their full potential.

Also, there is a natural reticence among scientists to comment publicly on the quality of research that is outside their area of professional competence. Again, the history and sociology of science provide many examples of where individuals in the same field (who may be competitors, or may be protegés) have expressed bias ${ }^{3-5}$.

Thus, by using real or potential eminence as a criterion for protest, we greatly restrict the number of scholars who might be enlisted to the cause and, as Gerald Holton $^{6}$ has shown, only a small fraction of the scientific community shows "societal concerns".
It is curious that it has taken so long for some scientists to learn the lesson of Amnesty International, which has had some relative success in dealing with unjust incarceration or torture in authorita rian regimes of the right, left and centre There is a need for a strict apolitica approach, emphasizing deviation from common humanitarian ideals as expressed in the writings of both capitalist and socialist states. It is desirable to avoid unnecessary labelling or stereotyping, for example Gliner's ${ }^{1}$ "dangerous 'bourgeois ideology"”.

It is ironic that it was none other than Sakharov himself who complained that the unfair political slant of an earlier item in Nature "almost cancelled its in Nature "almost cancelled its Department of Zoology, C.M. ANn BAKer

University of Adelaide,

South Australia, 5001

1. Gliner, E.B. Nature 318, 513 (1985)

. Council for Science and Society Scholarly Freedom and Human Rights (Barry Rose, London, 1977).

Martin, B. The Bias of Science (Society for Social Responsibility in Science, Canberra, Australia, 1979)

Manwell C. \& Baker C. M.A. Search 12, 151-160 (1981)

5. Peters, D.B. \& Ceci, S.J. in Peer Commentary on Peer Review (ed. Harnad, S.) 3-11 (Cambridge University Press, 1982)

6. Holton, G. The Scientific Imagination Case Studies, espe cially pp. 234-235 (Cambridge University Press, 1978). . Sakharov, A. Nature 288, 112 (1980).

\section{Evolution again}

SrR-Attacks on and defence of Charles Darwin and his evolutionary views are obviously unavoidable as a result of the current debate about the biological evolution. Dover recently emphasized the importance of the phenomenon of stasis in this context ${ }^{1}$. I, however, would like to suggest that Darwin, for psychological and strategic reasons, of which he was perhaps not quite aware, excluded, $a$ priori, stasis as well as evolutionary jumps from his definite theory of transmutation. Although in retrospect Darwin's contemporaries might appear to have been prepared for the shift of epistems, the successful introduction of the idea of transmutation into the scientific community was a huge task for Darwin; it was even held to be responsible for his mysterious invalidism ${ }^{2}$. From his conviction of perma nent and gradual change in nature, Darwin eventually got the required intellectual energy to accomplish his project. The orthodoxy, as is well known, advocated the fixity of species and acts of special creation - the first can be considered as an extreme form of stasis, the latter of jumps. Whereas Darwin himself hinted at the phenomenological similarity between special creation and evolutionary jumps ${ }^{3}$, the implication of this similarity between stasis and the fixity of species should also be considered in the discussion of the development of his theory. Darwin's strategy then, was to propose an opposite picture of the living world rather than explain the old issues in terms of transmutation. If he had incorporated a plausible explanation of stasis into his theory, the orthodoxy would probably have used it as an argument in favour of the fixity of species.

This approach was counteracted by Darwin's obsessional reverence for facts, whether they suited him or not. Consequently in The Origin of Species Darwin included significant tenets of the new hypothesis of punctuated equilibrium as was shown by Rhodes ${ }^{4}$.

Mirko Majer

Mozartstrasse 5 ,

D-8510 Fürth/Bayern, FRG

\footnotetext{
. Dover, G.A. Nature 318, 19 (1985)

2. Colp, R. To be an Invalid (Chicago and London, 1977).

Darwin, C. The Origin of Species by Means of Natural Selec tion 6 th edn, 424 (Murray, London, 1880).

Rhodes, F.H.T. Nature 305, 269 (1983).
}

\section{Classical relativity}

SIR-H. Aspden (Nature 318, 317; 1985) says: "Relativity, in its classical sense, will undoubtedly survive, but the real question is whether the test of time will continue to support Einstein's requirement that each and every relatively-moving observer constitutes his own personal reference frame for the locally-applicable laws of physics". Everyone would agree with the latter suggestion, but what is the meaning of the statement "Relativity, in its classical sense, will undoubtedly survive?"

N.J. KOLYVODIAKOS

"Studies in Physics",

12 William King Street,

GR-11253 Athens,

Greece

H. AsPden RePLiEs-N.J. Kolyvodiakos has questioned the meaning of "Relativity, in its classical sense". This was a reference to the pre-Einstein version of relativity. This is that physical phenomena measured exclusively within the confines of a system in non-accelerated motion will not reveal that motion to an observer transported with the system.

Einstein went beyond this by relying on the additional axiom that light propagates in free space with the same speed relative to all observers. This axiom was not restricted to light speed in the immediate vicinity of the observer or to observers sharing the motion of the apparatus by which light speed was measured. The observers could be in relative motion, even though close together and viewing the same ray of light, however remote it might be. This has given scope for paradox and, though most of the theoretical criticism has been parried, it encourages the search for experimental violation of Einstein's version of relativity.

Department of Electrical Engineering,

University of Southampton, Southampton SO9 5NH, UK 